TITLE:

\title{
Instrumentation for dual-probe scanning near-field optical microscopy
}

\section{$\operatorname{AUTHOR}(\mathrm{S}):$}

Kaneta, Akio; Fujimoto, Ryo; Hashimoto, Tsuneaki; Nishimura, Katsuhito; Funato, Mitsuru; Kawakami, Yoichi

\section{CITATION:}

Kaneta, Akio ... [et al]. Instrumentation for dual-probe scanning nearfield optical microscopy. Review of Scientific Instruments 2012, 83(8): 083709.

\section{ISSUE DATE:}

2012-08-23

URL:

http://hdl.handle.net/2433/187966

\section{RIGHT:}

(c) 2012 American Institute of Physics. This article may be downloaded for personal use only. Any other use requires prior permission of the author and the American Institute of Physics. 


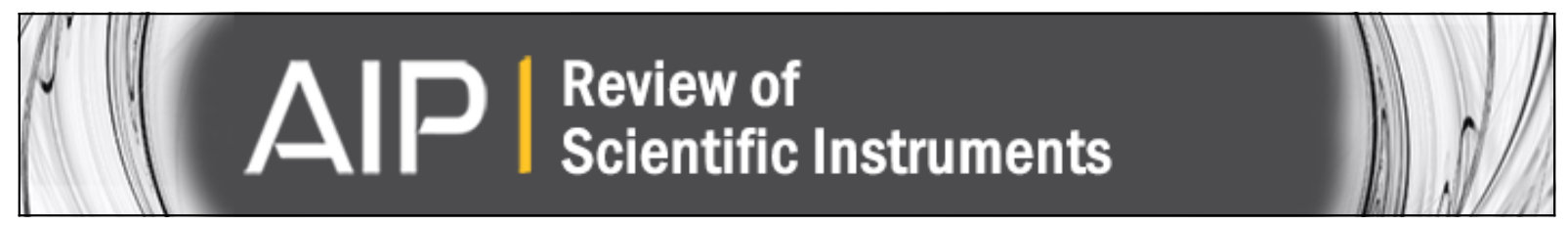

\section{Instrumentation for dual-probe scanning near-field optical microscopy}

A. Kaneta, R. Fujimoto, T. Hashimoto, K. Nishimura, M. Funato, and Y. Kawakami

Citation: Review of Scientific Instruments 83, 083709 (2012); doi: 10.1063/1.4737883

View online: http://dx.doi.org/10.1063/1.4737883

View Table of Contents: http://scitation.aip.org/content/aip/journal/rsi/83/8?ver=pdfcov

Published by the AIP Publishing

\section{Articles you may be interested in}

Near-field scanning optical microscopy and time-resolved optical characterization of epitaxial lateral overgrown c -plane and a -plane GaN

Appl. Phys. Lett. 89, 262117 (2006); 10.1063/1.2424677

Investigation of excess carrier diffusion in nitride semiconductors with near-field optical microscopy

Appl. Phys. Lett. 74, 850 (1999); 10.1063/1.123387

Role of localized and extended electronic states in InGaN/GaN quantum wells under high injection, inferred from near-field optical microscopy

Appl. Phys. Lett. 73, 493 (1998); 10.1063/1.121911

Local optical spectroscopy of self-assembled quantum dots using a near-field optical fiber probe to induce a localized strain field

Appl. Phys. Lett. 72, 2081 (1998); 10.1063/1.121282

Near-field scanning optical spectroscopy of an InGaN quantum well

Appl. Phys. Lett. 72, 927 (1998); 10.1063/1.120875

\section{AlP Re-register for Table of Content Alerts}




\title{
Instrumentation for dual-probe scanning near-field optical microscopy
}

\author{
A. Kaneta, R. Fujimoto, T. Hashimoto, K. Nishimura, M. Funato, and Y. Kawakami \\ Department of Electronic Science and Engineering, Kyoto University, Kyoto 615-8510, Japan
}

(Received 23 March 2012; accepted 5 July 2012; published online 23 August 2012)

\begin{abstract}
To investigate local carrier motions, we developed a dual-probe scanning near-field optical microscope (SNOM) with two fiber probes where one is for photoexcitation and the other is for light collection. This instrumentation is based on two important techniques: the design of probe structures and distance control between the sample surface and the two probes. A finite-difference time-domain method numerically analyzed and optimized the design for high efficiency photoexcitation and light collection, while a dual band modulation realized distance control. Real time detection of the oscillations of the probe tips using different frequencies independently controls the distance between the probe tip and the sample surface as well as the distance between the two probes. Thus, the collection probe can be scanned around an illumination probe without destroying the probe tips. To demonstrate our SNOM, we performed photoluminescence spectroscopy under the dual-probe configuration and observed carrier motions in an InGaN quantum well. ( 2012 American Institute of Physics. [http://dx.doi.org/10.1063/1.4737883]
\end{abstract}

\section{INTRODUCTION}

Scanning probe microscopy (SPM) can observe not only the precise surface morphology of a material ${ }^{1,2}$ but also various nanometer-scale surface characteristics such as density of states, ${ }^{3,4}$ electrostatic capacitance, ${ }^{5}$ friction force, ${ }^{6}$ magnetic force, ${ }^{7}$ and optical property. ${ }^{8}$ In recent years, optoelectronic properties on the nanometer scale have received increased attention for many reasons. One is that device size has been reduced to a few tens of nanometers, ${ }^{9,10}$ and carrier transport or propagation in these devices is affected by local structures such as process flaws, crystal defects, and structural domain boundaries. Furthermore, in blue light emitting diodes based on InGaN quantum wells (QWs), self-formed potential fluctuations have been reported to play a role in the recombination mechanism in InGaN-based nanostructures. ${ }^{11-15}$ However, conventional SPM based on one probe cannot observe actual carrier motions, which diffuse from the probe tip.

Consequently, a scanning tunneling microscope (STM), ${ }^{16-24}$ an atomic force microscope (AFM) ${ }^{25-27}$ and a scanning near-field optical microscope (SNOM) (Refs. 15, 28, and 29) with multiple probes have been developed to characterize the correlation between local structures and optoelectronic characteristics. Even with these technologies, the three-body problem between the sample surface and the two probes remains. Several methods have been proposed to resolve this issue, including monitoring the probes with an optical microscope or a scanning electron microscope (SEM), comparing the surface morphologies obtained by the two probes, and measuring the shape of the probe tip with another probe. Decreasing the distance between the two probes to less than a few micrometers is difficult when monitoring the probes with an optical microscope ${ }^{24,27}$ because the spatial resolution is restricted by the diffraction limit. Although the multiple-tip STM installed in SEM achieved $30 \mathrm{~nm}$ of minimum distance between two probes, ${ }^{22}$ in many cases, precisely controlling the position of the probe tip in SEM is difficult due to the charging effect of the sample. ${ }^{16-21}$ Moreover, electron beam irradiation during SEM observations generates carriers, which make it hard to measure the intrinsic electrical properties of the sample. To compare surface morphologies obtained with two probes, ${ }^{23,25,26}$ specific structures must be fabricated on the sample surface, and the relative position of each probe cannot be determined in real time without specific image data analysis. ${ }^{23}$ Moreover, when the sample surface morphology is rough, the method measuring the form of the probe tip using another probe ${ }^{28,29}$ is problematic to distinguish the surface morphology from that of the probe tip. Because a technique to concurrently control the distance between the probe tip and sample surface as well as between the probe tips has yet to be established, the lateral motion of the carriers or elemental excitations as well as their spatial distribution near an illumination $(I)$ probe cannot be observed.

In this study, we develop a dual-probe $(D)$ SNOM with distance control, which can independently regulate the distance between the probe tip and sample surface as well as the distance between the probe tips in real time. Moreover, photoluminescence (PL) mapping is realized with a pump and probe configuration in the spatial domain.

\section{MICROSCOPE DESIGN}

Conventional optical microscopes, including confocal microscopes, perform both photoexcitation and light collection in the far-field through an objective lens. Consequently, spatial resolution is restricted by the diffraction limit. On the other hand, SNOM has realized a high spatial resolution, which exceeds the diffraction limit. In addition, selecting the appropriate photoexcitation and light collection configurations in SNOM (Table I and Fig. 1) can provide information related to local carrier diffusion and/or recombination processes. ${ }^{15}$ In the $I$ mode, photoexcitation is performed through the $I$ probe aperture, and photons, which are generated by radiative recombination of photogenerated carriers, 
TABLE I. Relationship between photoexcitation and light collection configurations in the optical microscope and SNOM.

\begin{tabular}{lll}
\hline \hline & Excitation & Detection \\
\hline Optical microscope & Far-field & Far-field \\
$I$ mode & $I$ probe & Far-field \\
$C$ mode & Far-field & $C$ probe \\
$I-C$ mode & $I$ probe & $I$ probe \\
$D$ mode & $I$ probe & $C$ probe \\
\hline \hline
\end{tabular}

are collected in the far-field. Therefore, the signal intensity in the $I$ mode reflects the ratio of the number of carriers that recombine radiatively and nonradiatively. However, the spatial resolution of the $I$ mode is limited by the carrier diffusion length if it is larger than the aperture diameter.

In the collection $(C)$ mode, photoexcitation is performed in the far-field, and photon signals are collected in the $C$ probe aperture. In the illumination-collection $(I-C)$ mode, the aperture diameter determines the spatial resolution because both photoexcitation and light collection are performed through identical $I$ probe apertures. The PL peak positions directly reflect the potential energy under the $I$ probe aperture, but it is difficult in the $I-C$ mode to attribute a weak PL intensity to nonradiative recombination processes or to diffusion of photogenerated carriers outside the probe aperture.

In the $D$ mode, a sample is photoexcited through the $I$ probe aperture, and then photon signals from the carriers that diffuse outside the $I$ probe aperture are collected by the $C$ probe aperture (Fig. 1). Because the $I$ probe is fixed at a specific position while the $C$ probe is scanned near the $I$ probe, the $D$ mode can visualize actual lateral motions of carriers or elemental excitations.

Figure 2(a) shows a diagram of our DSNOM PL and time-resolved (TR) PL setup. In our DSNOM, a second harmonic generation (SHG) of a tunable mode-locked Ti:sapphire laser and an InGaN laser diode (LD) are used for short pulse excitation and continuous-wave (cw) excitation, respectively. In TRPL measurements, the collected PL signals are introduced into a $30 \mathrm{~cm}$ single monochromator and detected by a streak camera. In steady state PL measurements, PL emitted by the sample is dispersed in a $50 \mathrm{~cm}$ single monochromator and detected by a liquid nitrogen cooled charge coupled device (CCD) detector. Thus, our system can acquire a PL spectrum at each measuring point.

Figure 2(b) is a schematic of our DSNOM. To improve the reproducibility of the measurement location and to avoid the creep effect of piezoelectric actuators, xyz-axis piezoelectric scanners equipped with capacitive sensors for position feedback are adopted in both the sample scan stage and $C$ probe scan stage. To measure the desired area in the sample, the piezoelectric scanners are mounted on the coarse motion stages, which consists of a manually-operated xy-axis micrometer stage and a stepper motor driven $\mathrm{z}$-axis linear stage. The closed-loop resolutions for the sample stage and for the $C$ probe scan stage in our DSNOM system were $\pm 1.6 \mathrm{~nm}$ and $\pm 3.0 \mathrm{~nm}$, respectively. These values were the standard deviations of the actual travel distance against a setting distance of $50 \mathrm{~nm}$, and were extracted from 3500-times measurements. Additionally, their position accuracies were $\pm 28 \mathrm{~nm}$ and $\pm 61 \mathrm{~nm}$, respectively, which were evaluated by measuring a groove spacing of $833 \mathrm{~nm}$ on a diffraction grating 150 times. An objective lens, which can independently move to the sample stage, is placed below the sample stage to collect PL in the $I$ mode or to make photoexcitation in the $C$ mode. Because the relative position between the $I$ probe tip and the objective lens does not change during the SNOM measurement, the photon signals can be detected in high sensitivity. The sample surface and probe positions are observed by the CCD camera with a large magnification telescopic lens. Additionally, to measure all the interesting positions in the scan area of the $I$ probe, the scan area of the $C$ probe covers that of the $I$ probe [Fig. 2(c)].

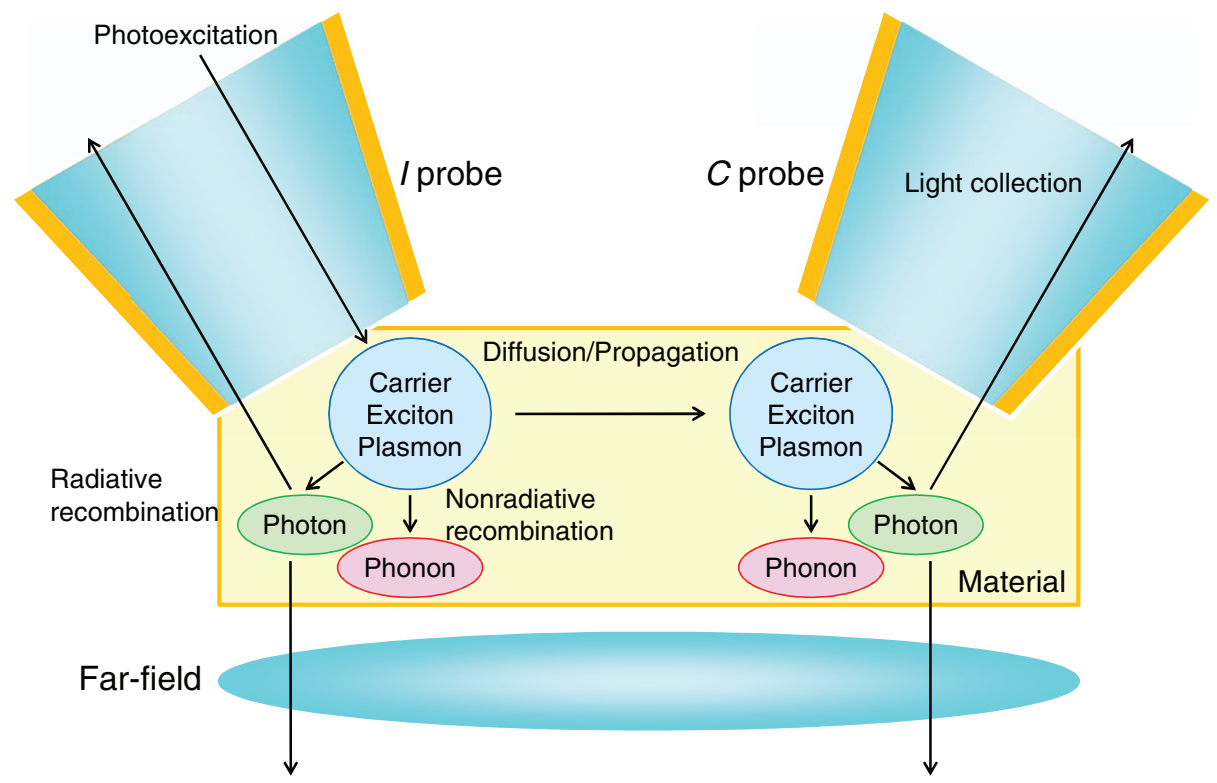

FIG. 1. Schematic of carrier motion and recombination processes in a material detected by the DSNOM. 
(a)

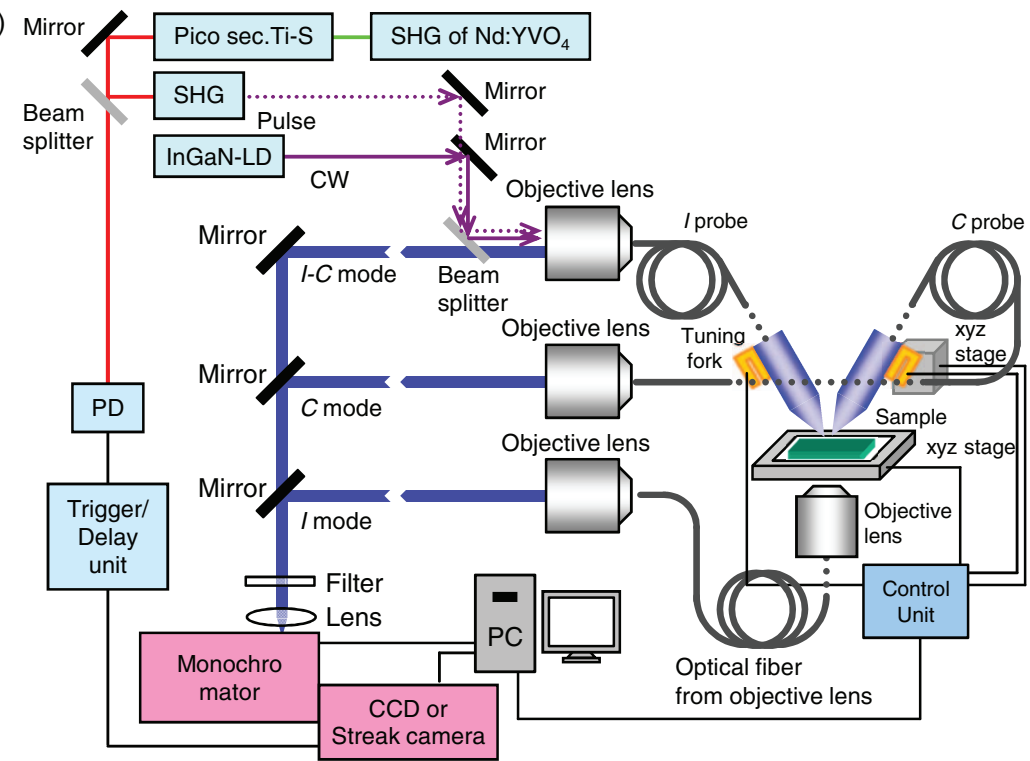

(b)

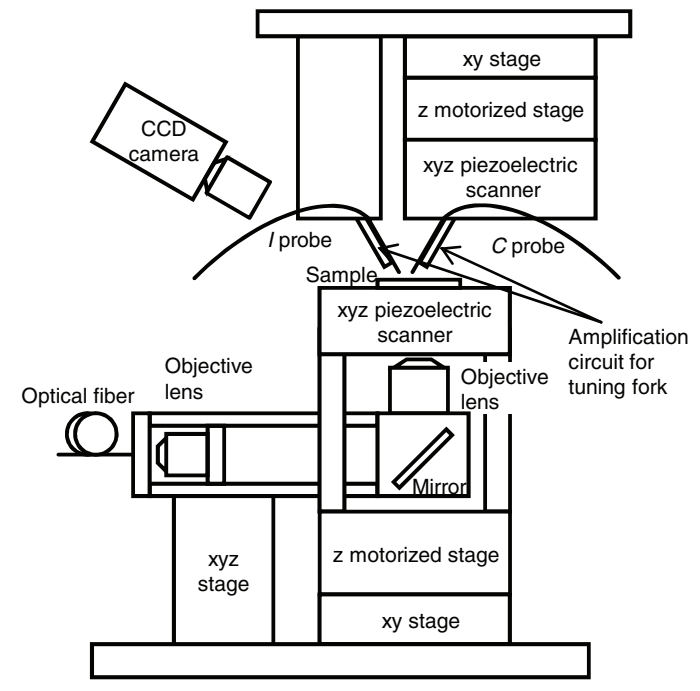

(c)

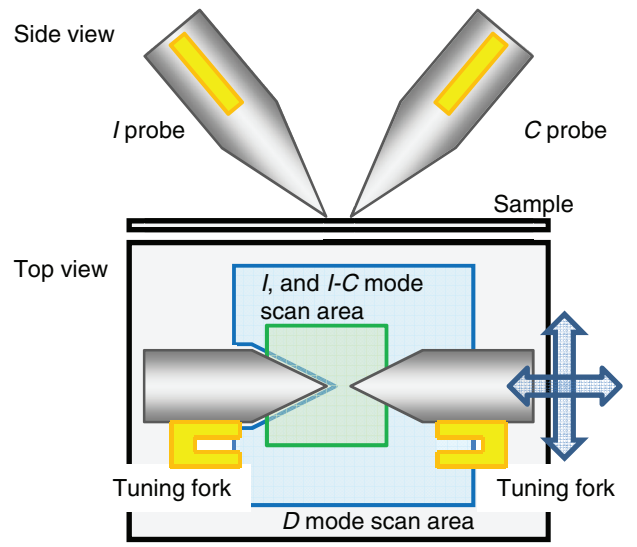

FIG. 2. (a) Diagram of our DSNOM PL setup. (b) Schematic layout of the DSNOM system. (c) Detailed configurations of the $I$ and $C$ probes, motion of the $C$ probe in the $D$ mode measurement, and correlation between the scan area of the $I$ and $I-C$ modes and that of the $D$ mode.

The damping of the oscillating probe tips by shear force has been widely used to control the distance between a probe tip and sample surface. This damping is often detected optically by focusing a laser beam on the probe tip and detecting its reflection by a photodiode. In a $D$ mode measurement, however, the two probes are located in close proximity and the
$C$ probe moves a few ten micrometers. Therefore, tracking of the $C$ probe by a laser beam is difficult. Hence, our system employs a non-optical shear force distance control technique. ${ }^{30}$ As shown in Fig. 2(c), each fiber probe is mounted on one arm of a quartz crystal tuning fork (TF), which is also used in quartz watches, and damping of the oscillating probe tip is 
detected as the change in the piezoelectric voltage produced at the electrode of TF. For a highly sensitive detection of the piezoelectric voltage, the quartz crystal TFs are connected to lab-built amplification circuits, which can compensate for stray capacitance in the TFs. ${ }^{31}$

\section{FIBER PROBE DESIGN}

To date, various probe tip structures for SNOM have been developed. ${ }^{32}$ Compared to a fiber probe with a singletapered core, a shoulder-shaped fiber probe with a doubletapered core realizes a higher light collection. ${ }^{33,34}$ Although the double-tapered core probe tip structure is widely used in the $I-C$ mode,${ }^{35}$ this probe is unsuited for DSNOM because the cladding with an approximate diameter of $10 \mu \mathrm{m}$ prevents the probe tips from approaching each other. As shown in Fig. 2(c), we selected pencil-shaped fiber probes where the probes are tilted at the same angle, but in opposite directions.

It has been predicted that the photoexcitation efficiency, light collecting efficiency, and spatial resolution depend on the cone angle $\theta$ of the probe tips ${ }^{34}$ as well as on the tilt angle $\varphi$ of the fiber probe. Therefore, we numerically analyzed the fiber probe structures using the finite-difference time-domain (FDTD) method. ${ }^{36}$ Figure 3 shows the structure of both the $C$ and $I$ probes and sample for calculating the photoexcitation and light collection efficiencies. Our calculation model reproduces the experimental condition of the near-field PL mapping for InGaN/GaN single (S) QW structures. ${ }^{15}$ Tables II and III list the calculation parameters. To calculate the photoexcitation efficiency, fiber probe is assumed to be a pencil-shaped structure with $100 \mathrm{~nm}$ diameter aperture covered by a $150 \mathrm{~nm}$ thick $\mathrm{Au}$ film. The wavelength of a light source is $405 \mathrm{~nm}$, which corresponds to the experimental condition to selectively photoexcite InGaN SQWs. The tilt angle $\varphi$ with respect to the surface normal was set to be half of the cone angle $\theta(2 \varphi=\theta)$ because this is the minimum value which is avoidable of the geometrical problem in the approach of each probe. The minimum distance between the tilted fiber probes and the sample surface is assumed to be $10 \mathrm{~nm}$. For this calculation, the coordinates are defined as $\left(x_{i}, y_{i}, z_{i}\right)$ with the origin shown in Fig. 3. The center of the $I$ probe aperture is located at $\left(\mathrm{X}_{\mathrm{i}}, \mathrm{Y}_{\mathrm{i}}, \mathrm{Z}_{\mathrm{i}}\right)=(0,0,10 \mathrm{~nm}$ $+200 \mathrm{~nm} \times \sin \varphi)$. The scattered light intensity is evaluated by integrating the Poynting vectors which pass a $20-n m-$

TABLE II. Parameters of the FDTD calculation for photoexcitation efficiency.

\begin{tabular}{lc}
\hline \hline Refractive index of fiber core (405 nm) & $1.470^{\mathrm{a}}$ \\
Refractive index of fiber clad (405 nm) & 1.465 \\
Refractive index of Au (real part) & $1.465^{\mathrm{b}}$ \\
Refractive index of Au (imaginary part) & $1.955^{\mathrm{b}}$ \\
Core diameter & $2.36 \mu \mathrm{m}$ \\
Clad diameter & $4.0 \mu \mathrm{m}$ \\
Aperture diameter & $100 \mathrm{~nm}$ \\
Metal film thickness for light shield & $150 \mathrm{~nm}$ \\
Laser wavelength & $405 \mathrm{~nm}$ \\
\hline
\end{tabular}

${ }^{\mathrm{a}}$ Reference 39.

${ }^{\mathrm{b}}$ Reference 40 .
TABLE III. Parameters of the FDTD calculation for light collection efficiency.

\begin{tabular}{lc}
\hline \hline Refractive index of fiber core $(520 \mathrm{~nm})$ & $1.461^{\mathrm{a}}$ \\
Refractive index of fiber clad $(520 \mathrm{~nm})$ & 1.456 \\
Refractive index of Au (real part) & $0.635^{\mathrm{b}}$ \\
Refractive index of Au (imaginary part) & $2.072^{\mathrm{b}}$ \\
Refractive index of GaN & $2.417^{\mathrm{c}}$ \\
Refractive index of InGaN & $2.673^{\mathrm{d}}$ \\
Core diameter & $2.36 \mu \mathrm{m}$ \\
Clad diameter & $4.0 \mu \mathrm{m}$ \\
Aperture diameter & $100 \mathrm{~nm}$ \\
Metal film thickness for light shield & $150 \mathrm{~nm}$ \\
Emission wavelength & $520 \mathrm{~nm}$ \\
\hline \hline
\end{tabular}

${ }^{\text {a Reference } 39}$

${ }^{\mathrm{b}}$ Reference 40 .

${ }^{\mathrm{c}}$ Reference 41 .

${ }^{\mathrm{d}}$ Reference 42 .

square monitor aligned along the $\mathrm{x}_{\mathrm{i}}$ or $\mathrm{y}_{\mathrm{i}}$ axes on the sample surface.

Figures 4(a) and 4(b) show the scattered light intensity $\left(I_{\text {scat }}\right)$ profiles for the $I$ probe along the $\mathrm{x}_{\mathrm{i}}$ and $\mathrm{y}_{\mathrm{i}}$ axes, respectively. Figures 4(c) and 4(d) show the dependence of the peak $I_{\text {scat }}$ and full width of half maximum (FWHM) on the cone angle for the $I$ probe extracted from the profiles, respectively. Although the peak $I_{\text {scat }}$ increases significantly when the cone angle is small, it becomes saturated when the cone angle is large. These phenomena can be explained as follows. For a small cone angle, the increase in the peak $I_{\text {scat }}$ is attributed to the shortening of the tapered region with a diameter less than the wavelength of light. However, for a large cone angle, the peak $I_{\text {scat }}$ tends to become saturated due to decreased propagation of the light from the fiber core to the tapered area. $^{34}$

Although the FWHM along the $\mathrm{x}_{\mathrm{i}}$ axis is slightly larger than that of the $y_{i}$ axis when the cone angle is larger than 70 degrees because the fiber probe is tilted in the $-\mathrm{x}_{\mathrm{i}}$ direction, the FWHMs along the both $x_{i}$ and $y_{i}$ axes increase almost linearly as the cone angle increases. The irradiation area of the scattered light spreads in the $+\mathrm{x}_{\mathrm{i}}$ direction because the distance between the probe aperture and sample surface increases as the cone angle increases.

The FDTD calculations for light collection and photoexcitation efficiencies have almost complementary layouts. The fiber probe collects the PL $(\lambda=520 \mathrm{~nm})$, which is assumed to be from a point-like non-polarized source whose size is $3 \times 3$ $\times 3 \mathrm{~nm}^{3}$. The PL collected by the probe aperture with $100 \mathrm{~nm}$ diameter propagates in the tapered region, which is covered by a $150 \mathrm{~nm}$ thick $\mathrm{Au}$ film, and is then guided to the core area of the fiber probe. The center of the $C$ probe aperture is located at $\left(\mathrm{X}_{\mathrm{c}}, \mathrm{Y}_{\mathrm{c}}, \mathrm{Z}_{\mathrm{c}}\right)=(0,0,10 \mathrm{~nm}+200 \mathrm{~nm} \times \sin \varphi)$. The intensity of the collected signal is evaluated by integrating the Poynting vector, which passes the monitor located $2 \mu \mathrm{m}$ away from the tapered region in the core area of the fiber probe.

Figure 5(a) shows the collected light intensity $\left(I_{\text {coll }}\right)$ profiles of the $C$ probe along the $\mathrm{x}_{\mathrm{c}}$ axis. Figures 5(b) and 5(c) show the peak $I_{\text {coll }}$ and FWHM extracted from the profiles as functions of the cone angle for the $C$ probe, respectively. The 
(a)

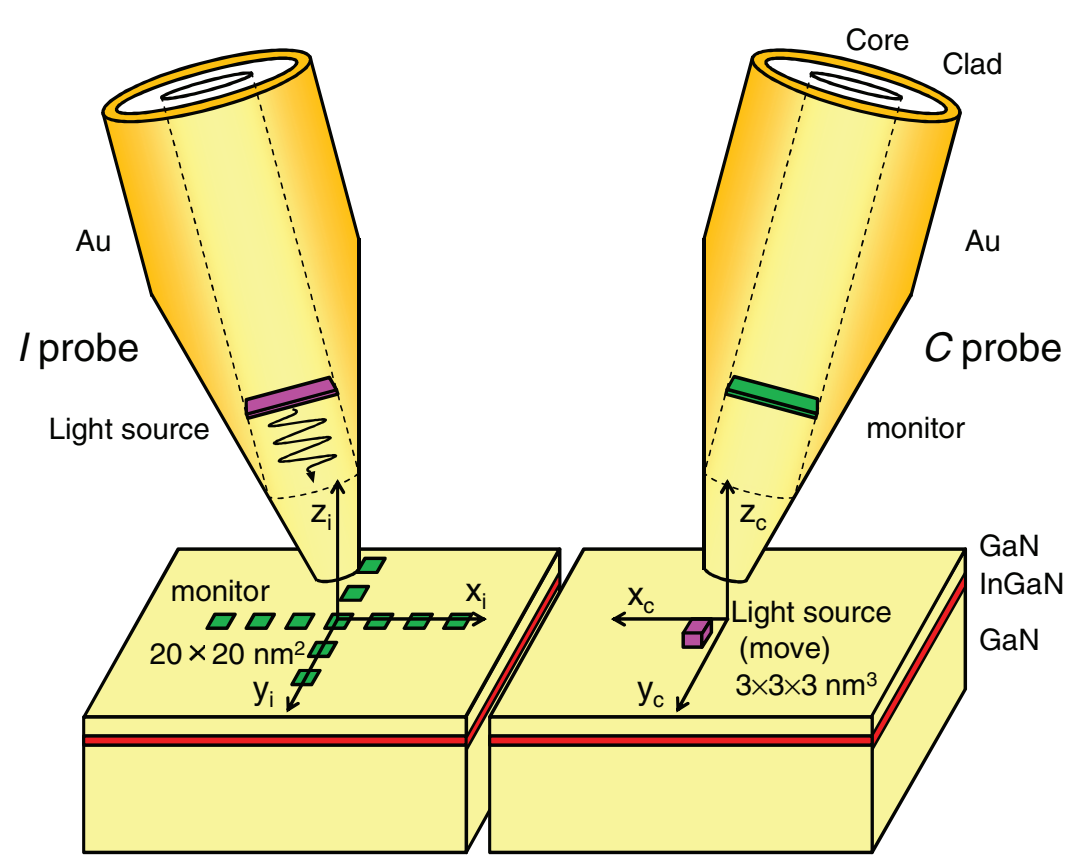

(b)

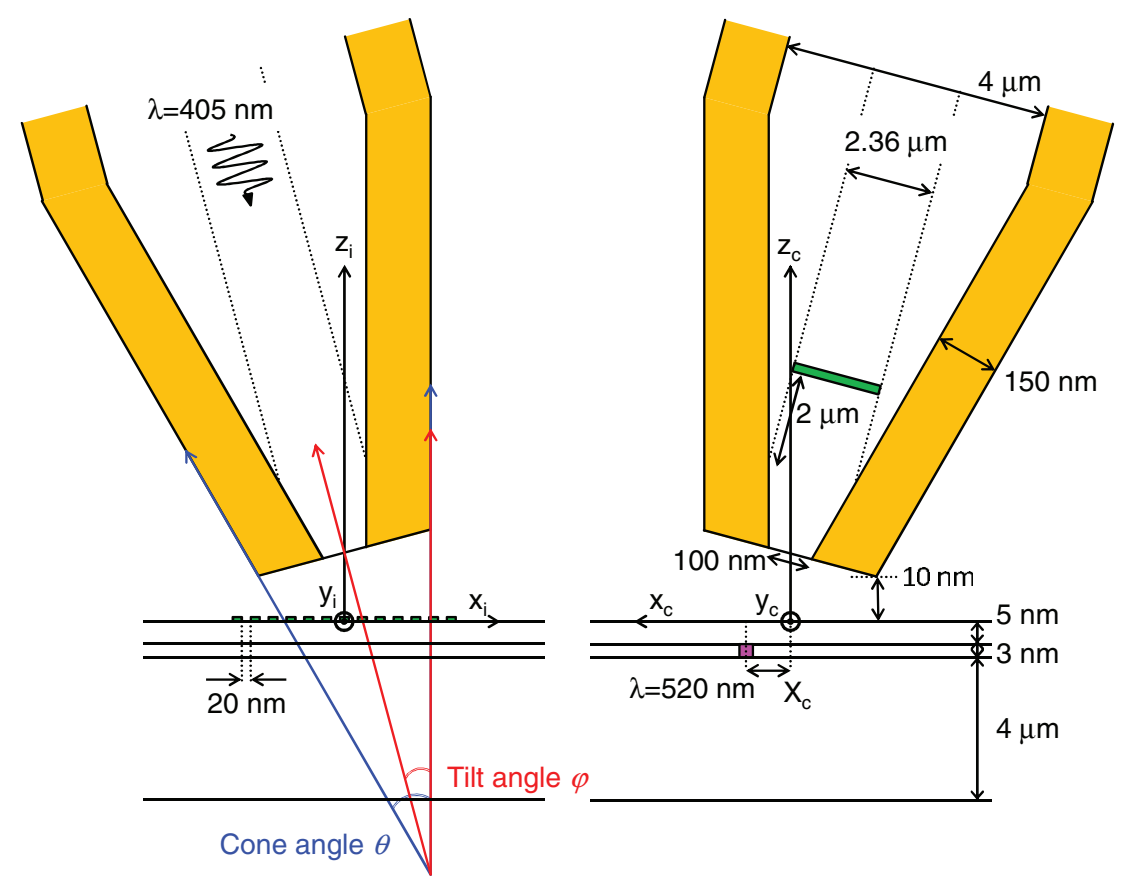

FIG. 3. (a) Three-dimensional and (b) cross-sectional views of fiber probes, light source, and monitor for the FDTD calculations of the photoexcitation efficiency and light collection efficiency.

cone angle dependences of the $I_{\text {coll }}$ profiles, peak $I_{\text {coll }}$, and FWHM of the light collection efficiency are similar to those for the photoexcitation efficiency because only the light propagates in the opposite direction.

After considering the compromising condition between the spatial resolution and the efficiencies of photoexcitation and light collection, numerical analyses indicate that the appropriate values for the cone angle and tilt angle are approximately 40 and 20 degrees, respectively. Consequently, we fabricated a pencil-shaped fiber probe with the desired cone angle using a dynamic etching method in which the location of fiber probe in etching fluid was unchanged while the temperature of the fluid was controlled. This technique enables the control of cone angle as shown in Fig. 6 because the meniscus part can be perpendicularly moved by volume change of etching fluid according with temperature change.

\section{DUAL BAND MODULATION (DBM) TECHNIQUE}

In this section, we describe the distance control system in our DSNOM. The diffusion lengths of excitons and plasmons are reported to be on the order of a few hundred $\mathrm{nm},{ }^{11,15,28,29}$ which is comparable to the geometric limit of the mutual fiber distance [Fig. 3(b)]. Therefore, 
(a)

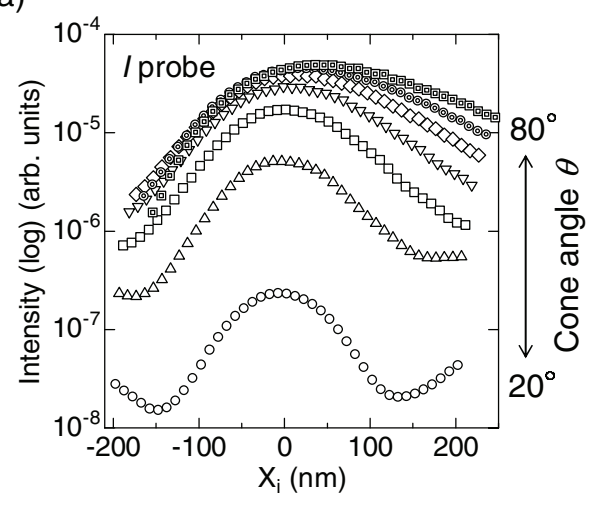

(c)

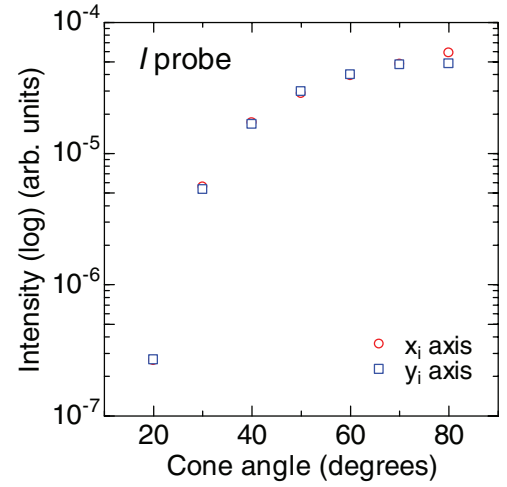

(b)

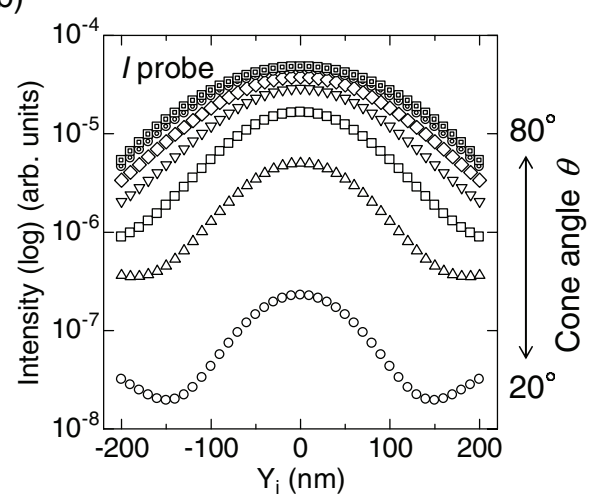

(d)

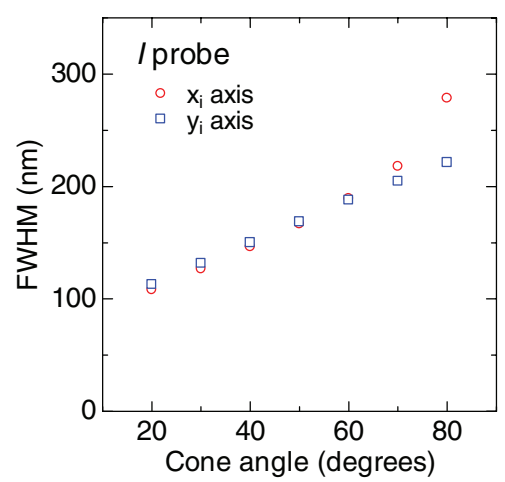

FIG. 4. $I_{\text {scat }}$ profiles of the $I$ probe for various cone angles along (a) the $\mathrm{x}_{\mathrm{i}}$ axis and (b) the $\mathrm{y}_{\mathrm{i}}$ axis. (c) Peak and (d) FWHM of the $I_{\text {scat }}$ as functions of the cone angle of the $I$ probe.

the two probe tips have to be as close as possible. Figures 7(a) and 7(b) show the dual band modulation (DBM) technique that we developed. To control the distance between the probe tip and the sample surface, the TFs of the $C$ and $I$ probes are oscillated with an amplitude $a_{\mathrm{r}}$ of $5 \mathrm{~nm}$ along the sample surface at a resonant angular frequency $\omega_{\mathrm{r}}$

(a)

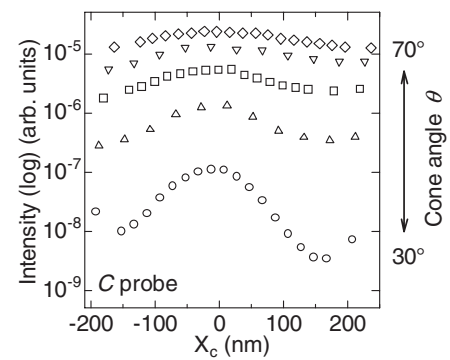

(b)

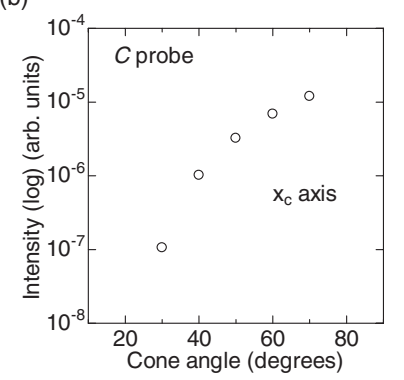

(c)

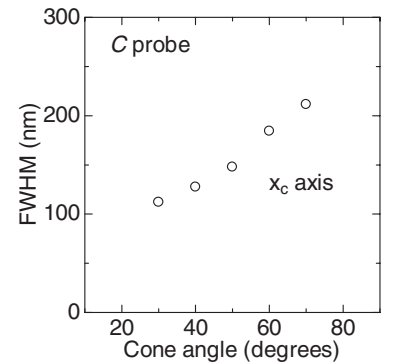

FIG. 5. (a) $I_{\text {coll }}$ profiles of the $C$ probe for various cone angles along the $\mathrm{x}_{c}$ axis. (b) Peak and (c) FWHM of the $I_{\text {coll }}$ as functions of the cone angle of the $C$ probe. $\left(f_{\mathrm{r}}=\frac{\omega_{\mathrm{r}}}{2 \pi} \sim 32.7 \mathrm{kHz}\right)$. On the other hand, to control the distance between the probe tips, the piezoelectric scanner for the $C$ probe is oscillated with an amplitude $a_{\mathrm{m}}$ of $50 \mathrm{~nm}$ at a different angular frequency $\omega_{\mathrm{m}}\left(f_{\mathrm{m}}=\frac{\omega_{\mathrm{m}}}{2 \pi} \sim 100 \mathrm{~Hz}\right)$ perpendicular to the resonant oscillation. The reduction in the shear-force induced piezoelectric voltage for each frequency is detected by the TF connected to each fiber probe.

Figure 8 shows (a) a block diagram of the DBM technique and the configurations of the $C$ and $I$ probes in the $D$ mode measurement where the $C$ probe is in a well-separated position (b) $\left(d_{\infty}, h_{0}\right)$ and in a closer position (c) $\left(d_{0}, h_{0}\right)$ in which the shear-force interaction between the probes appears. For the $D$ mode measurement, the coordinates are defined as $(\mathrm{x}, \mathrm{y}, \mathrm{z})$ shown in Figs. 8(b) and 8(c). In general, the piezoelectric signal induced by oscillating a probe tip with angular frequency $\omega$ and with amplitude $a$ in a free space is expressed as

$$
s=k a D \cos \omega t
$$
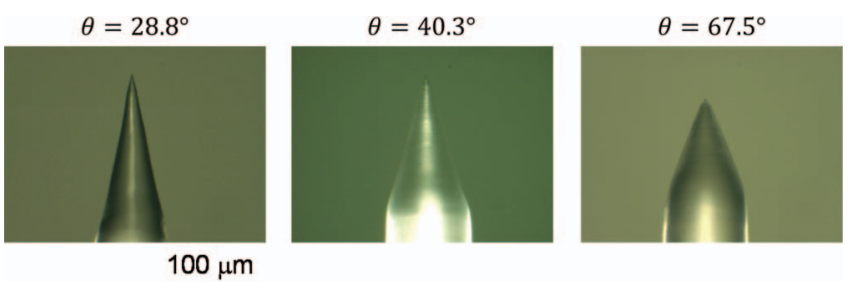

FIG. 6. Microscopic images of pencil-shaped fiber probes with cone angles of $28.8^{\circ}, 40.3^{\circ}$, and $67.5^{\circ}$. 
(a)

(b)
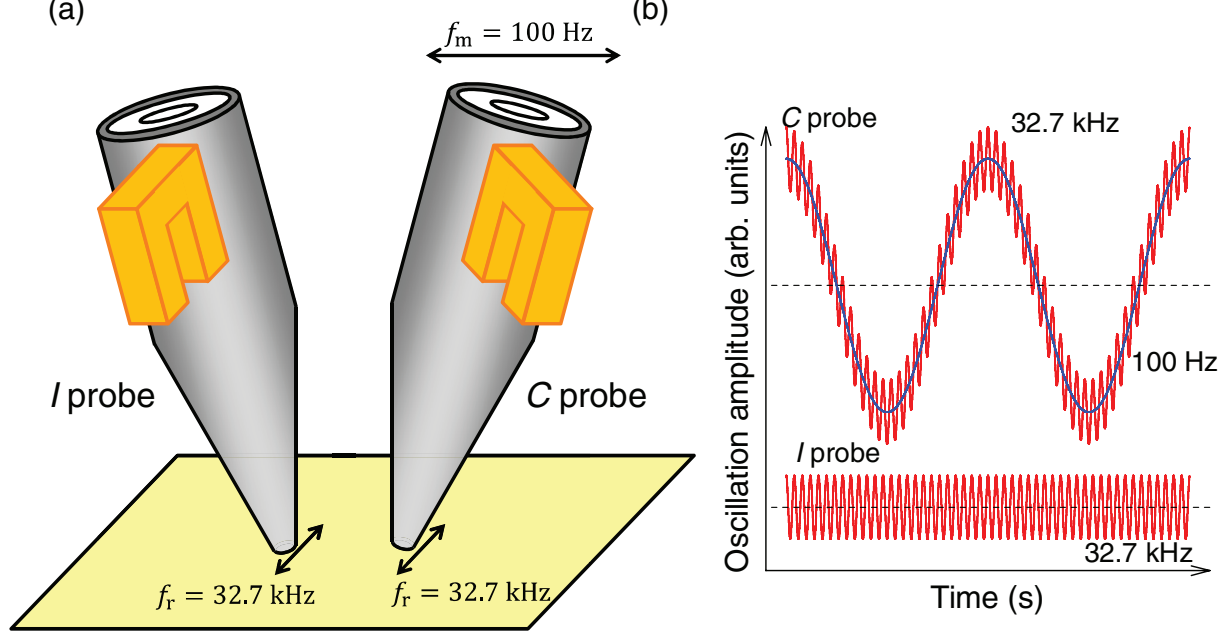

FIG. 7. (a) Directions of the resonant oscillations of the TFs in the $C$ and $I$ probes, and that of the modulation in the $C$ probe. (b) Oscillations are applied to the $C$ and $I$ probes in the DBM technique.

where $k$ is a proportional coefficient between signal $s$ and probe motion $a D \cos \omega t$. $D$ is a dimensionless parameter expressing the relative probe oscillation amplitude normalized to 1 when the distance to another object is well-separated, but it is monotonically reduced as the probe-object distance decreases, and becomes zero upon contact. ${ }^{37}$ When the $C$ probe is located at position $\left(d_{\infty}, h_{0}\right)$, the probe motion is restricted solely by the shear-forces induced by the interactions between the probe and the sample surface. Therefore, $D$ is expressed as

$$
D=f_{\mathrm{z}}(h),
$$

where $h$ is the probe-sample distance. As shown in Fig. 8(b), a modulation is applied to the $C$ probe along the $\mathrm{x}$ direction with modulation amplitude $a_{\mathrm{m}}$ and modulation angular frequency $\omega_{\mathrm{m}}$. Because the modulation is applied without changing $h$ and the variation of $h$ by the resonant oscillation is sufficiently small $(\sim 6.25 \mathrm{fm}), h$ can be replaced by a constant value $h_{0}$. Therefore, substituting Eq. (2) into Eq. (1) gives the piezoelectric signal produced by the $C$ probe motion as

$$
s\left(h_{0}, t\right)=k_{\mathrm{r}} a_{\mathrm{r}} f_{\mathrm{z}}\left(h_{0}\right) \cos \left(\omega_{\mathrm{r}} t+\varphi_{1}\right)+k_{\mathrm{m}} a_{\mathrm{m}} f_{\mathrm{z}}\left(h_{0}\right) \cos \omega_{\mathrm{m}} t,
$$

where $k_{\mathrm{r}}$ and $k_{\mathrm{m}}$ depend on the frequency $\left(\frac{k_{\mathrm{r}}}{k_{\mathrm{m}}} \sim 100\right.$ in this case). $\varphi_{1}$ is the phase difference between the $\omega_{\mathrm{m}}$ and $\omega_{\mathrm{r}}$. This signal contains the both $\omega_{\mathrm{r}}$ and $\omega_{\mathrm{m}}$. Therefore, we adopted a heterodyne technique to obtain the signal corresponding to each frequency. Multiplying Eq. (3) with $\cos \omega_{\mathrm{r}} t$ gives following equation:

$$
\begin{aligned}
s\left(h_{0}, t\right) \cos \omega_{\mathrm{r}} t= & {\left[k_{\mathrm{r}} a_{\mathrm{r}} f_{\mathrm{z}}\left(h_{0}\right) \cos \left(\omega_{\mathrm{r}} t+\varphi_{1}\right)\right.} \\
& \left.+k_{\mathrm{m}} a_{\mathrm{m}} f_{\mathrm{z}}\left(h_{0}\right) \cos \omega_{\mathrm{m}} t\right] \cos \omega_{\mathrm{r}} t .
\end{aligned}
$$

The signal $s_{1}\left(h_{0}\right)$, which is related to the distance between the $C$ probe and sample, can be obtained by removing all the $\mathrm{AC}$ components through a low pass filter (LPF),

$$
s_{1}\left(h_{0}\right)=\frac{1}{2} k_{\mathrm{r}} a_{\mathrm{r}} f_{\mathrm{z}}\left(h_{0}\right) .
$$

Therefore, the distance between the $C$ probe and the sample can be controlled.

When the $C$ probe is located at position $\left(d_{0}, h_{0}\right)$ [Fig. 8(c)], the probe motion is restricted by the shear forces induced by both the probe-sample and probe-probe interactions. Therefore, $D$ can be expressed as

$$
D=f_{1}(d) f_{\mathrm{z}}(h),
$$

where $d$ is the distance between the probe tips, and $f_{1}(d)$ is a function expressing the probe-probe interaction. If the oscillation amplitudes are sufficiently small, then $f_{1}(d)$ can be approximated as

$$
f_{1}(d)=f_{1}\left(d_{0}\right)+f_{1}^{\prime}\left(d_{0}\right)\left(d-d_{0}\right) .
$$

Furthermore, the $C$ probe motion at position $d_{0}$ is modulated by the resonant frequency of the $I$ probe through the shear force. Therefore, the distance between probes $d$ is expressed as

$$
\begin{aligned}
d= & \sqrt{\left(d_{0}+a_{\mathrm{m}} \cos \omega_{\mathrm{m}} t\right)^{2}+\left[a_{\mathrm{r}} \cos \left(\omega_{\mathrm{r}} t+\varphi_{1}\right)-a_{\mathrm{r}} \cos \left(\omega_{\mathrm{r}} t+\varphi_{2}\right)\right]^{2}} \\
\sim & d_{0}+a_{\mathrm{m}} \cos \omega_{\mathrm{m}} t+\frac{1}{2}\left(P_{1}+P_{2} \cos \omega_{\mathrm{m}} t\right)\left[a_{\mathrm{r}} \cos \left(\omega_{\mathrm{r}} t+\varphi_{1}\right)\right. \\
& \left.-a_{\mathrm{r}} \cos \left(\omega_{\mathrm{r}} t+\varphi_{2}\right)\right]^{2}, \text { where } \\
P_{1}= & \frac{1}{T} \int_{-T / 2}^{T / 2} \frac{1}{d_{0}+a_{\mathrm{m}} \cos \omega_{\mathrm{m}} t} d t, \\
P_{2}= & \frac{1}{a_{\mathrm{m}}}\left(2-d_{0} \frac{2}{T} \int_{-T / 2}^{T / 2} \frac{1}{d_{0}+a_{\mathrm{m}} \cos \omega_{\mathrm{m}} t} d t\right)
\end{aligned}
$$

$\varphi_{2}$ is the phase difference between the $\omega_{\mathrm{r}}$ in the $I$ probe and $\omega_{\mathrm{m}}$. Therefore, the piezoelectric signal produced by the $C$ probe motion can be given by substituting Eqs. (5), (6), and (7) into Eq. (1).

$$
\begin{aligned}
s\left(d_{0}, h_{0}, t\right)= & f_{\mathrm{z}}\left(h_{0}\right)\left\{f_{1}\left(d_{0}\right)+f_{1}^{\prime}\left(d_{0}\right) a_{\mathrm{m}} \cos \omega_{\mathrm{m}} t\right. \\
& +\frac{1}{2}\left(P_{1}+P_{2} \cos \omega_{\mathrm{m}} t\right)\left[a_{\mathrm{r}} \cos \left(\omega_{\mathrm{r}} t+\varphi_{1}\right)\right. \\
& \left.\left.-a_{\mathrm{r}} \cos \left(\omega_{\mathrm{r}} t+\varphi_{2}\right)\right]^{2}\right\} \\
& \times\left[k_{\mathrm{r}} a_{\mathrm{r}} \cos \left(\omega_{\mathrm{r}} t+\varphi_{1}\right)+k_{\mathrm{m}} a_{\mathrm{m}} \cos \omega_{\mathrm{m}} t\right] .
\end{aligned}
$$


(a)

a)
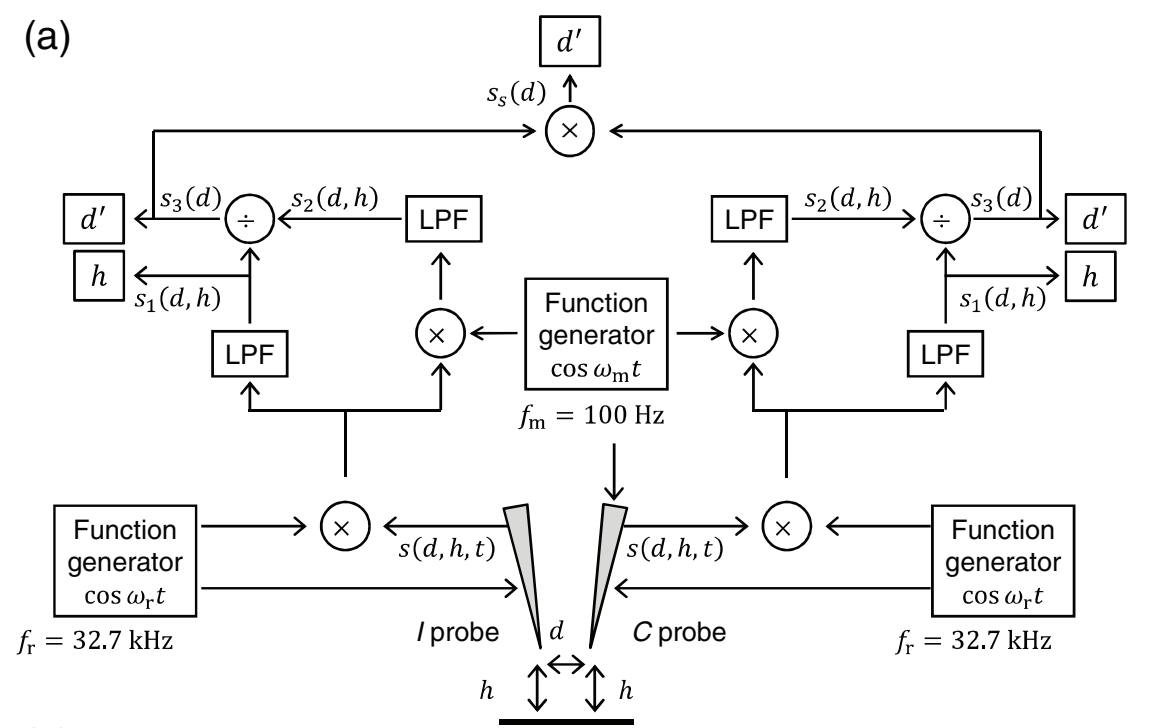

(b)

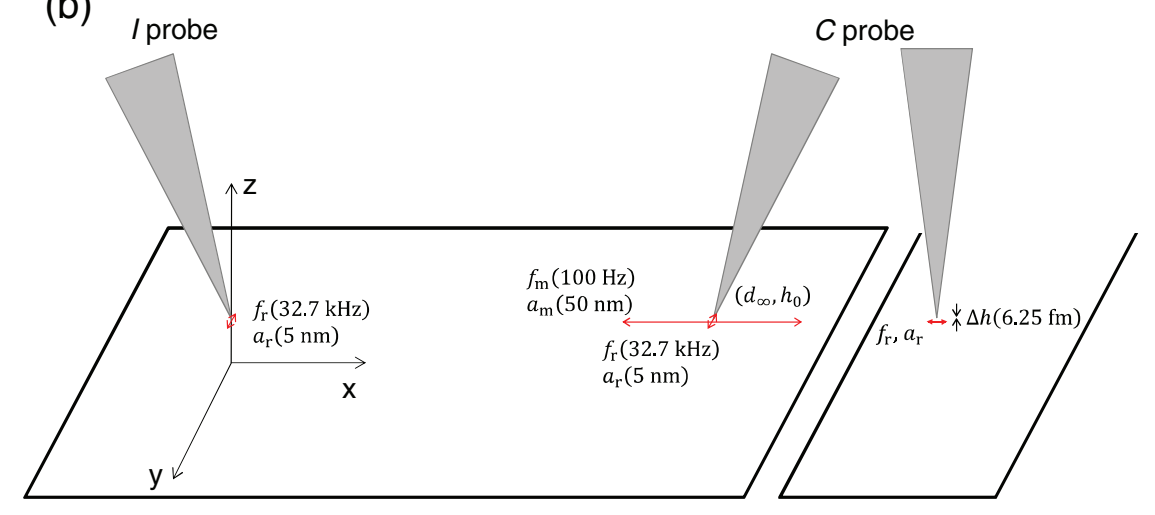

(c)

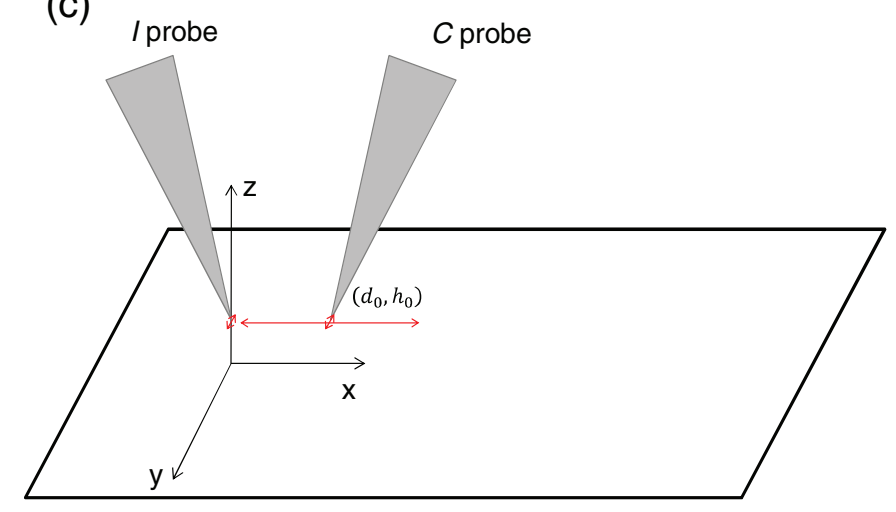

FIG. 8. (a) Block diagram of distance control in the DSNOM. Coordinates and oscillating directions and widths of both probes in the $D$ mode when the $C$ probe is in (b) the $\left(d_{\infty}, h_{0}\right)$ position and (c) the $\left(d_{0}, h_{0}\right)$ position.

Again, we adopted a heterodyne technique to obtain a signal corresponding to each frequency. Multiplying Eq. (8) with $\cos \omega_{\mathrm{r}} t$ gives

$$
\begin{aligned}
s\left(d_{0}, h_{0}, t\right) \cos \omega_{\mathrm{r}} t= & f_{\mathrm{z}}\left(h_{0}\right)\left\{f_{1}\left(d_{0}\right)+f_{1}^{\prime}\left(d_{0}\right) a_{\mathrm{m}} \cos \omega_{\mathrm{m}} t\right. \\
& +\frac{1}{2}\left(P_{1}+P_{2} \cos \omega_{\mathrm{m}} t\right)\left[a_{\mathrm{r}} \cos \left(\omega_{\mathrm{r}} t+\varphi_{1}\right)\right. \\
& \left.\left.-a_{\mathrm{r}} \cos \left(\omega_{\mathrm{r}} t+\varphi_{2}\right)\right]^{2}\right\} \\
& \times\left[k_{\mathrm{r}} a_{\mathrm{r}} \cos \left(\omega_{\mathrm{r}} t+\varphi_{1}\right)\right. \\
& \left.+k_{\mathrm{m}} a_{\mathrm{m}} \cos \omega_{\mathrm{m}} t\right] \cos \omega_{\mathrm{r}} t
\end{aligned}
$$

For the $s_{1}\left(d_{0}, h_{0}\right)$ signal, which corresponds to the distance between the $C$ probe and the sample, it is obtained by removing the AC component in the Eq. (9) through the LPF,

$$
\begin{aligned}
s_{1}\left(d_{0}, h_{0}\right)= & \frac{1}{16} k_{\mathrm{r}} a_{\mathrm{r}} f_{\mathrm{z}}\left(h_{0}\right)\left[f_{1}^{\prime}\left(d_{0}\right) P_{1} a_{\mathrm{r}}^{2} G\left(\varphi_{1}, \varphi_{2}\right)\right. \\
& \left.+8 f_{\mathrm{r}}\left(d_{0}\right) \cos \varphi_{1}\right]
\end{aligned}
$$

where

$$
\begin{aligned}
G\left(\varphi_{1}, \varphi_{2}\right)= & \cos \left(-\varphi_{1}+2 \varphi_{2}\right)-2 \cos \left(-2 \varphi_{1}+\varphi_{2}\right) \\
& -4 \cos \varphi_{2}+5 \cos \varphi_{1} .
\end{aligned}
$$


It should be noted that the $s_{1}\left(d_{0}, h_{0}\right)$ signal does not contribute to the stable operation of DSNOM because the signal depends on both the probe-sample and probe-probe distances.

Because $k_{\mathrm{m}} a_{\mathrm{m}}$ is much smaller than $k_{\mathrm{r}} a_{\mathrm{r}}$ $\left(k_{\mathrm{m}} a_{\mathrm{m}} / k_{\mathrm{r}} a_{\mathrm{r}} \sim 0.1\right)$ in our DSNOM system, it is difficult to detect the signal $s_{2}\left(d_{0}, h_{0}\right)$ with the heterodyne method by simply multiplying by $\cos \omega_{\mathrm{m}} t$. Therefore, we multiplied Eq. (9) by $\cos \omega_{\mathrm{m}} t$ to give

$$
\begin{aligned}
s( & \left.d_{0}, h_{0}, t\right) \cos \omega_{\mathrm{r}} t \cos \omega_{\mathrm{m}} t \\
= & f_{\mathrm{z}}\left(h_{0}\right)\left\{f_{1}\left(d_{0}\right)+f_{1}^{\prime}\left(d_{0}\right) a_{\mathrm{m}} \cos \omega_{\mathrm{m}} t+\frac{1}{2}\left(P_{1}+P_{2} \cos \omega_{\mathrm{m}} t\right)\right. \\
& \left.\times\left[a_{\mathrm{r}} \cos \left(\omega_{\mathrm{r}} t+\varphi_{1}\right)-a_{\mathrm{r}} \cos \left(\omega_{\mathrm{r}} t+\varphi_{2}\right)\right]^{2}\right\} \\
& \times\left[k_{\mathrm{r}} a_{\mathrm{r}} \cos \left(\omega_{\mathrm{r}} t+\varphi_{1}\right)+k_{\mathrm{m}} a_{\mathrm{m}} \cos \omega_{\mathrm{m}} t\right] \cos \omega_{\mathrm{r}} t \cos \omega_{\mathrm{m}} t .
\end{aligned}
$$

Then the signal $s_{2}\left(d_{0}, h_{0}\right)$ is obtained by removing the $\mathrm{AC}$ component through the LPF,

$$
\begin{aligned}
s_{2}\left(d_{0}, h_{0}\right)= & \frac{1}{32} k_{\mathrm{r}} a_{\mathrm{r}} f_{1}^{\prime}\left(d_{0}\right) f_{\mathrm{z}}\left(h_{0}\right) \\
& \times\left[P_{2} a_{\mathrm{r}}^{2} G\left(\varphi_{1}, \varphi_{2}\right)+8 a_{\mathrm{m}}^{2} \cos \varphi_{1}\right] .
\end{aligned}
$$

Moreover, dividing Eq. (11) by Eq. (10) gives the following equation:

$$
\begin{aligned}
s_{3}\left(d_{0}\right) & =\frac{s_{2}\left(d_{0}, h_{0}\right)}{s_{1}\left(d_{0}, h_{0}\right)} \\
& =\frac{f_{1}^{\prime}\left(d_{0}\right)\left[P_{2} a_{\mathrm{r}}^{2} G\left(\varphi_{1}, \varphi_{2}\right)+8 a_{\mathrm{m}}^{2} \cos \varphi_{1}\right]}{2 f_{1}^{\prime}\left(d_{0}\right) P_{1} a_{\mathrm{r}}^{2} G\left(\varphi_{1}, \varphi_{2}\right)+16 f_{1}\left(d_{0}\right) \cos \varphi_{1}} .
\end{aligned}
$$

In this way, a term solely dependent on $d_{0}$ is successfully obtained. Consequently, the probe-sample and probe-probe distances can be independently controlled using the signals of $s_{1}\left(h_{0}\right)$ and $s_{3}\left(d_{0}\right)$.

Figures 9(a) and 9(b) show the experimental signals of $s_{1}\left(d_{0}, h_{0}\right)$ and $s_{3}\left(d_{0}\right)$ for each probe, respectively, while Fig. 9(c) shows the signal $s_{\mathrm{s}}\left(d_{0}\right)$ obtained by multiplying the signal $s_{3}\left(d_{0}\right)$ of the $I$ probe with that of the $C$ probe. All data are plotted as functions of the $C$ probe location, while the $I$ probe is stationary. $s_{\mathrm{s}}\left(d_{0}\right)$ is discussed below. The signals can be classified into three parts: (i), (ii), and (iii). In part (i), $s_{1}\left(d_{0}, h_{0}\right)$ and $s_{3}\left(d_{0}\right)$ are nearly constant, corresponding to part (i) in Fig. 9(d) where the probes are adequately separated and shear force is not detected. In part (ii), the intensity of $s_{3}\left(d_{0}\right)$ decreases, while that of $s_{1}\left(d_{0}, h_{0}\right)$ remains constant, indicating that the $C$ and $I$ probes can come within a distance of a few tens of nanometers [part (ii) in Fig. 9(d)]. Finally, in part (iii), all the signal intensities decrease, and the reduction in the $s_{1}\left(d_{0}, h_{0}\right)$ signal intensity of the $C$ probe is larger than that of the $I$ probe. These results suggest that the $C$ probe is pushed down by the $I$ probe due to the close contact, which is schematically depicted in part (iii) of Fig. 9(d). Therefore, these results indicate that the DBM technique is more sensitive to probe tips approaching each other than the method recognizing the probe tips from topographic signals.

Figure 10 shows the scan procedure for our DSNOM system using a DBM technique. The $I$ probe is fixed at a specific position while the $C$ probe is scanned around the $I$ probe.

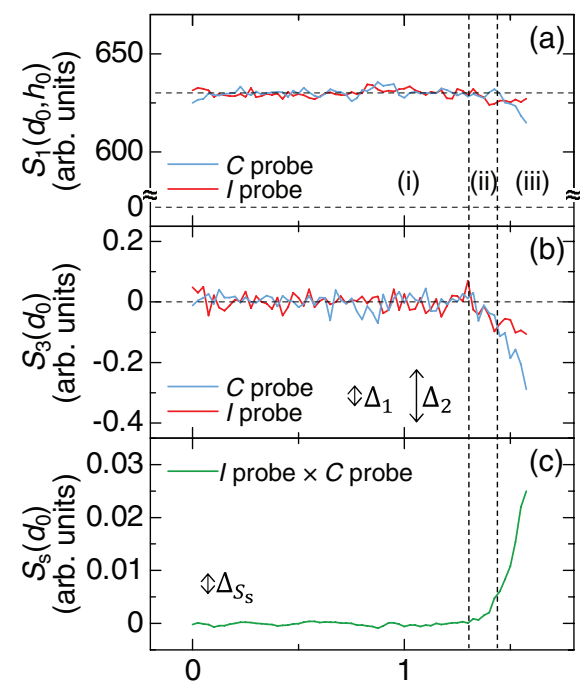

Travel distance of $C$ probe along $\mathrm{x}$ axis $(\mu \mathrm{m})$ (d) (i)

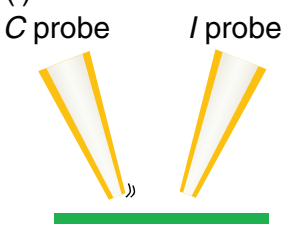

(ii)

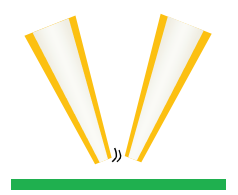

(iii)

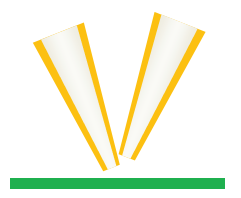

FIG. 9. (a) Piezoelectric signals $s_{1}\left(d_{0}, h_{0}\right)$ with the resonant frequency of the TFs $\left[f_{\mathrm{r}} \approx 32.7 \mathrm{kHz}\right]$ detected by the $I$ and $C$ probes. (b) Piezoelectric $s_{3}\left(d_{0}\right)$ signals with the modulation frequency $\left[f_{\mathrm{m}} \approx 100 \mathrm{~Hz}\right]$ detected by the $I$ and $C$ probes. (c) $s_{\mathrm{s}}\left(d_{0}\right)$ signal obtained by multiplying $s_{3}\left(d_{0}\right)$ of the $I$ probe with that of the $C$ probe. (d) Schematic of the relative positions in (i), (ii), and (iii) of the $C$ and $I$ probes.

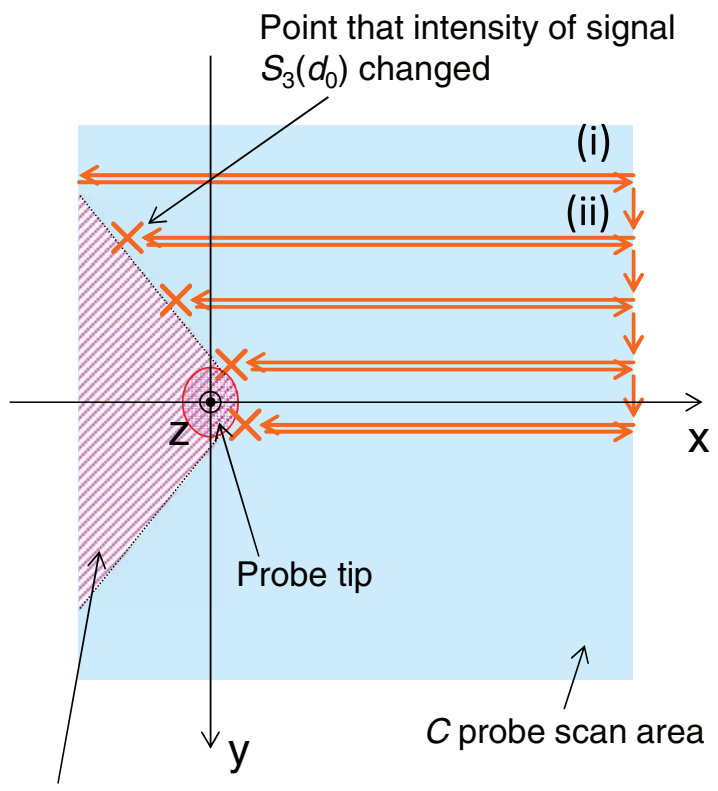

Forbidden area by / probe

FIG. 10. Detailed scan procedure of our DSNOM system using the DBM technique. Hyperbolic shape indicates the forbidden area due to the shade of the $I$ probe. 
(a)

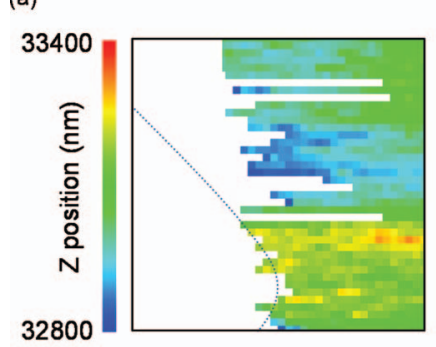

(c)

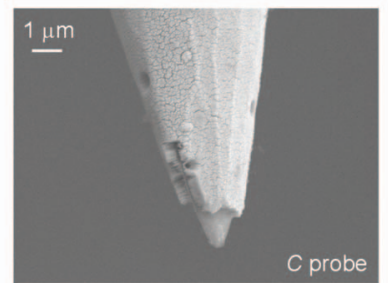

(b)

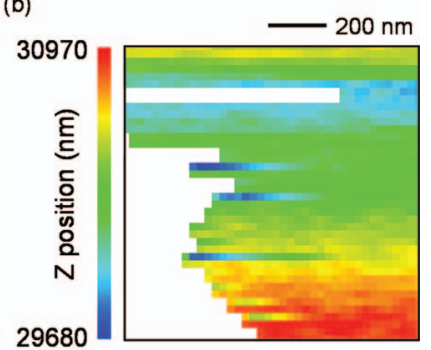

(d)

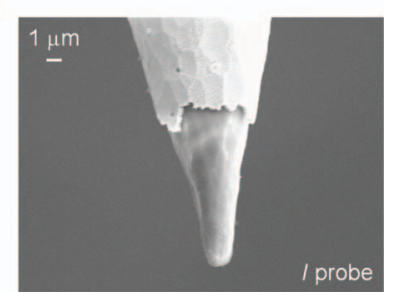

FIG. 11. Topographic images of InGaN/GaN SQW obtained by scanning near the $I$ probe with the $C$ probe using the DBM technique when the threshold value is set as (a) $\Delta_{1}$ and (b) $\Delta_{2}$. SEM images of (c) the $C$ probe tip and (d) the $I$ probe tip after the measurement.

When the $s_{3}\left(d_{0}\right)$ variation is smaller than the threshold value $\Delta$, the $C$ probe moves to the edge of the scan area and then it returns to the starting position as shown in line (i). Another approach begins by pushing down the initial position by a certain distance. When the $s_{3}\left(d_{0}\right)$ variation is greater than $\Delta$ at the position shown by the $\mathrm{X}$ in Fig. 10, the $C$ probe stops approaching the $I$ probe and returns to the initial position. As shown in line (ii), this process is repeated. Figure 10 shows the forbidden area of the approach, the border of which is a hyperbolic curve in the ideal case.

Figure 11 shows topographic images of an InGaN/GaN SQW acquired by scanning the $C$ probe around the $I$ probe. The settings are for $\Delta=\Delta_{1}$ [Fig. 11(a)] and $\Delta=\Delta_{2}$ [Fig. 11(b)], whose values are shown in Fig. 9(b). As shown in Fig. 11(a), the $C$ probe returns to the initial position without approaching the vicinity of the $I$ probe at many points. Such mis-approaches occur because $\Delta_{1}$ is too low, and it is easily exceeded by the $s_{3}\left(d_{0}\right)$ intensity due to an electrical and/or a vibrational noise. On the other hand, as shown in Fig. 11(b), when $\Delta_{2}$ is high, such a problem can be circumvented to some extent, but another problem arises, which can been seen in the images in the forbidden area. The $C$ probe possibly come in contact with the $I$ probe, and may push the $I$ probe up or down. As the result, the metal film and probe tip are broken [Figs. 11(c) and 11(d)]. Difficulty in controlling the probeprobe distance is attributed to the $\mathrm{S} / \mathrm{N}$ ratio of the $s_{3}\left(d_{0}\right)$ signal.

Therefore, to control the distance between the probes without the influence of noise, we propose that the $s_{3}\left(d_{0}\right)$ signal of the $I$ probe is multiplied by that of the $C$ probe because the sudden noise of a signal in either probe can be canceled because the possibility of such an outbreak simultaneously occurring in both probes is very rare. Figure 9 (c) shows the result of the multiplied $s_{\mathrm{s}}\left(d_{0}\right)$ signal. The $\mathrm{S} / \mathrm{N}$ ratio, which is improved, allows part (ii) to be clearly identified. Therefore, the edge of $C$ probe can be approached to the area separated

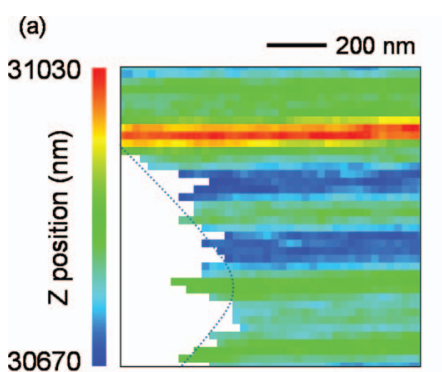

(b)

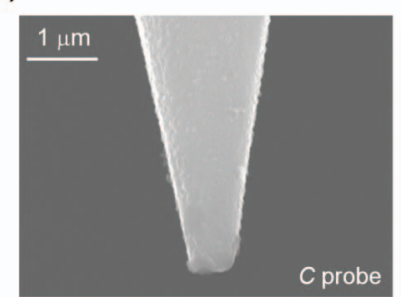

(c)

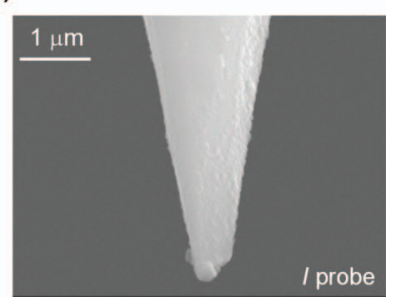

FIG. 12. (a) Topographic image obtained by scanning near the $I$ probe with the $C$ probe using a modified DBM technique. SEM images of (b) the $C$ probe tip and (c) the $I$ probe tip after the measurement.

$20 \mathrm{~nm}$ from that of the $I$ probe because the change of shearforce signal is detectable in this range. ${ }^{37}$

Figure 12(a) shows a topographic image of an InGaN SQW obtained by scanning near the $I$ probe with the $C$ probe using the modified DBM technique [ $s_{\mathrm{s}}\left(d_{0}\right)$-based control]. Figures 12(b) and 12(c) show SEM images of the $C$ and $I$ probe tips after the scan. Unlike mapping using the preliminary DBM technique [ $s_{3}\left(d_{0}\right)$-based control], the mis-approach problem is drastically improved, and neither tip has observable damage. Consequently, we adopted the modified DBM technique to investigate the carriers and elemental excitation motions near the $I$ probe in detail.

\section{OBSERVATION OF CARRIER DIFFUSION IN AN INGAN SQW}

In this section, we demonstrate the carrier diffusion process in an InGaN SQW using our DSNOM system. The sample is a $3 \mathrm{~nm}$ thick InGaN/GaN SQW grown on an epitaxially laterally overgrown $\mathrm{GaN}$ template by metalorganic chemical vapor deposition. The macroscopic PL peak of this sample was located at about $520 \mathrm{~nm}$ (green) at RT, which corresponds to an In composition of $25 \%$.

Pencil-shaped fiber probes with $200 \mathrm{~nm}$ diameter apertures, which are coated by $100 \mathrm{~nm}$ thick $\mathrm{Cr} / \mathrm{Au} / \mathrm{Al}$ multilayers, are used to illuminate the sample and to collect PL. The excitation source is an InGaN LD emitting at $405 \mathrm{~nm}$ to selectively photoexcite the InGaN active layers. The spatial resolution in this experimental ranged from 120 to $150 \mathrm{~nm}$ which is defined as the FWHM evaluated by fitting the cross-sectional PL intensity profile obtained in the $I-C$ mode with Gaussian distribution. This resolution is smaller than the aperture diameter of fiber probe. The mechanism of realizing such a high spatial resolution has not been well understood. It is possible that achievement of such a high spatial resolution is attributed to the high-NA-lens like effect at the SNOM probe tip. ${ }^{38}$ For all measurements, the estimated mean carrier density within the probe aperture is about $1 \times 10^{17} \mathrm{~cm}^{-3}$. In the $D$ mode 
(a)
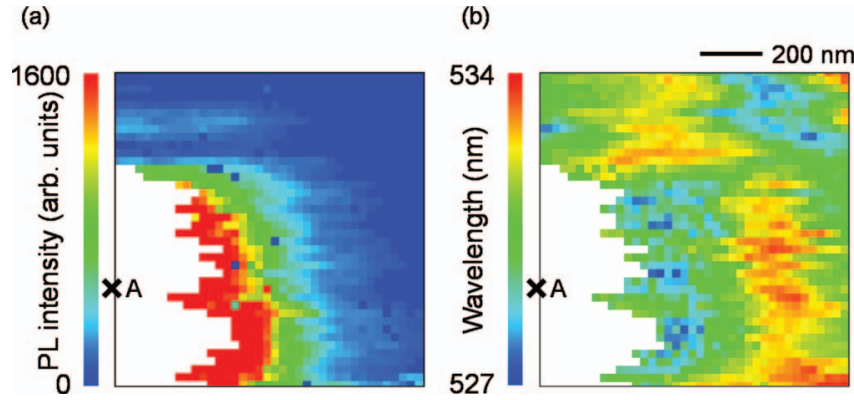

FIG. 13. (a) Spatial distribution of the PL intensity and (b) PL peak wavelength in the $D$ mode. In (a) and (b), the white color and position A denote the shadow and position of the $I$ probe, respectively.

measurement, the $I$ probe is fixed at a specific position while the $C$ probe is scanned around the $I$ probe.

Figures 13(a) and 13(b) show the spatial distribution of the PL intensity and the PL peak wavelength in the $D$ mode in the green emitting InGaN SQW, respectively. The white areas and A positions in Figs. 13(a) and 13(b) represent the edge of the $I$ probe and the center of the $I$ probe aperture position, respectively. The PL intensity distribution shows carrier motions occur unisotropically due to potential fluctuations in the InGaN SQW. The correlation with the PL peak wavelength suggests that the long-range motion is driven to the longer wavelength area. As previously discussed, ${ }^{15}$ the situation is complicated because carrier recombination is linked to many processes such as localization, anti-localization, and distributions of both radiative and non-radiative centers. However, it is noteworthy that not only the topographic image near the $I$ probe, but also PL mapping can be obtained without destroying the probe tips using the modified DBM technique.

\section{SUMMARY}

We developed a DSNOM with highly efficient photoexcitation and light collection probes for the $D$ mode which were designed by FDTD method. Additionally, we developed a DBM technique to independently control the probe-probe distance and the probe-sample distance in real time without specific structures on the sample surface. Then we experimentally confirmed this technique. Both topographic and PL images are obtained near the $I$ probe without destroying the probe tips.

\section{ACKNOWLEDGMENTS}

The authors would like to acknowledge Dr. Y. Narukawa and Dr. T. Mukai at Nichia Corporation for providing the SQW samples. This work was supported by a Grant-in-Aid for Scientific Research from the Japan Society for the Promotion of Science.

${ }^{1}$ G. Binnig, H. Rohrer, Ch. Gerber, and E. Weibel, Phys. Rev. Lett. 49, 57 (1982).

${ }^{2}$ G. Binnig, H. Rohrer, Ch. Gerber, and E. Weibel, Phys. Rev. Lett. 50, 120 (1983).

${ }^{3}$ G. Binnig, K. H. Frank, H. Fuchs, N. Garcia, B. Reihl, H. Rohrer, F. Salvan, and A. R. Williams, Phys. Rev. Lett. 55, 991 (1985).
${ }^{4}$ R. S. Becker, J. A. Golovchenko, D. R. Hamann, and B. S. Swartzentruber, Phys. Rev. Lett. 55, 2032 (1985).

${ }^{5}$ M. Nonnenmacher, M. P. O'Boyle, and H. K. Wickramasinghe, Appl. Phys. Lett. 58, 2921 (1991)

${ }^{6}$ C. M. Mate, G. M. McClelland, R. Erlandsson, and S. Chiang, Phys. Rev. Lett. 59, 1942 (1987).

${ }^{7}$ Y. Martin and H. K. Wickramasinghe, Appl. Phys. Lett. 50, 1455 (1987).

${ }^{8}$ E. Betzig and J. K. Trautman, Science 257, 189 (1992).

${ }^{9}$ T. Sekitani, Y. Noguchi, U. Zschieschang, H. Klauk, and T. Someya, Proc. Natl. Acad. Sci. U.S.A. 105, 4976 (2008).

${ }^{10}$ S. Natarajan, M. Armstrong, M. Bost, R. Brain, M. Brazier, C.-H. Chang, V. Chikarmane, M. Childs, H. Deshpande, K. Dev, G. Ding, T. Ghani, O. Golonzka, W. Han, J. He, R. Heussner, R. James, I. Jin, C. Kenyon, S. Klopcic, S.-H. Lee, M. Liu, S. Lodha, B. McFadden, A. Murthy, L. Neiberg, J. Neirynck, P. Packan, S. Pae, C. Parker, C. Pelto, L. Pipes, J. Sebastian, J. Seiple, B. Sell, S. Sivakumar, B. Song, K. Tone, T. Troeger, C. Weber, M. Yang, A. Yeoh, and K. Zhang, International Electron Devices Meeting Technical Digest, San Francisco, California, 2008, p. 1.

${ }^{11}$ Y. Kawakami, A. Kaneta, K. Omae, Y. Narukawa, and T. Mukai, Progress in Nano-Electro-Optics IV: Characterization of Nano-Optical Materials and Optical Near-Field Interactions, edited by Motoichi Ohtsu (SpringerVerlag, Berlin, 2005), pp. 83-125.

${ }^{12}$ A. Hangleiter, F. Hitzel, C. Netzel, D. Fuhrmann, U. Rossow, G. Ade, and P. Hinze, Phys. Rev. Lett. 95, 127402 (2005).

${ }^{13}$ A. Kaneta, M. Funato, and Y. Kawakami, Phys. Rev. B 78, 125317 (2008).

${ }^{14}$ Y. Yamada, T. Saito, N. Kato, E. Kobayashi, T. Taguchi, H. Kudo, and H. Okagawa, Phys. Rev. B 80, 195202 (2009).

${ }^{15}$ A. Kaneta, T. Hashimoto, K. Nishimura, M. Funato, and Y. Kawakami, Appl. Phys. Express 3, 102102 (2010).

${ }^{16}$ I. Shiraki, F. Tanabe, R. Hobara, T. Nagao, and S. Hasegawa, Surf. Sci. 493, 633 (2001).

${ }^{17}$ T. Kanagawa, R. Hobara, I. Matsuda, T. Tanikawa, A. Natori, and S. Hasegawa, Phys. Rev. Lett. 91, 036805 (2003).

${ }^{18}$ Y. Kajihara, T. Hihara, K. Sumiyama, and K. Motojima, Jpn. J. Appl. Phys. 44, 6867 (2005).

${ }^{19}$ H. Okino, I. Matsuda, R. Hobara, Y. Hosomura, S. Hasegawa, and P. A. Bennett, Appl. Phys. Lett. 86, 233108 (2005).

${ }^{20}$ K. Takami, M. Akai-Kasaya, A. Saito, M. Aono, and Y. Kuwahara, Jpn. J. Appl. Phys. 44, L120 (2005).

${ }^{21}$ O. Kubo, Y. Shingaya, M. Nakaya, M. Aono, and T. Nakayama, Appl. Phys. Lett. 88, 254101 (2006)

${ }^{22}$ S. Yoshimoto, Y. Murata, K. Kubo, K. Tomita, K. Motoyoshi, T. Kimura, H. Okino, R. Hobara, I. Matsuda, S. Honda, M. Katayama, and S. Hasegawa, Nano Lett. 7, 956 (2007).

${ }^{23}$ S. Higuchi, H. Kuramochi, O. Laurent, T. Komatsubara, S. Machida, M. Aono, K. Obori, and T. Nakayama, Rev. Sci. Instrum. 81, 073706 (2010).

${ }^{24}$ S. Yoshimoto, T. Tsutsui, K. Mukai, and J. Yoshinobu, Rev. Sci. Instrum. 82, 093902 (2011).

${ }^{25}$ N. Satoh, E. Tsunemi, Y. Miyato, K. Kobayashi, S. Watanabe, T. Fujii, K. Matsushige, and H. Yamada, Jpn. J. Appl. Phys. 46, 5543 (2007).

${ }^{26}$ E. Tsunemi, N. Satoh, Y. Miyato, K. Kobayashi, K. Matsushige, and H. Yamada, Jpn. J. Appl. Phys. 46, 5636 (2007).

${ }^{27}$ N. Kin, K. Takai, and K. Honda, Jpn. J. Appl. Phys. 47, 4638 (2008).

${ }^{28}$ R. Dallapiccola, C. Dubois, A. Gopinath, F. Stellacci, and L. Dal Negro, Appl. Phys. Lett. 94, 243118 (2009).

${ }^{29}$ X. Ren, A. Liu, C. Zou, L. Wang, Y. Cai, F. Sun, G. Guo, and G. Guo, Appl. Phys. Lett. 98, 201113 (2011).

${ }^{30}$ K. Karrai and R. D. Grober, Appl. Phys. Lett. 66, 1842 (1995).

${ }^{31}$ J. Rychen, T. Ihn, P. Studerus, A. Herrmann, K. Ensslin, H. J. Hug, P. J. A. van Schendel, and H. J. Guntherodt, Rev. Sci. Instrum. 71, 1695 (2000).

${ }^{32}$ M. Ohtsu, J. Lightwave Technol. 13, 1200 (1995).

${ }^{33}$ T. Saiki, S. Mononobe, M. Ohtsu, N. Saito, and J. Kusano, Appl. Phys. Lett. 68, 2612 (1996).

${ }^{34}$ K. Sawada, H. Nakamura, H. Kambe, and T. Saiki, IEICE Trans. Electron. E85-C, 2055 (2002).

${ }^{35}$ T. Saiki and K. Matsuda, App. Phys. Lett. 74, 2773 (1999).

${ }^{36}$ K. S. Yee, IEEE Trans. Antennas Propag. 14, 320 (1966).

${ }^{37}$ E. Betzig, P. L. Finn, and J. S. Weiner, Appl. Phys. Lett. 60, 2484 (1992).

${ }^{38}$ T. Saiki, K. Nishi, and M. Ohtsu, Jpn. J. Appl. Phys. 37, 1638 (1998).

${ }^{39}$ I. H. Malitson, J. Opt. Soc. Am. 55, 1205 (1965).

${ }^{40}$ P. B. Johnson and R. W. Christy, Phys. Rev. B 6, 4370 (1972).

${ }^{41}$ E. Ejder, Phys. Status Solidi A 6, 445 (1971).

${ }^{42}$ G. M. Laws, E. C. Larkins, I. Harrison, C. Molloy, and D. Somerford, J. Appl. Phys. 89, 1108 (2001). 